\title{
The Impact Of Using Multi-Sensory Approach For Teaching Students With Learning Disabilities
}

\author{
Majeda Al Sayyed Obaid, Ph.D., Irbid National University, Jordan
}

\begin{abstract}
The purpose of this study is to investigate the effect of using the Multi-Sensory Approach for teaching students with learning disabilities on the sixth grade students' achievement in mathematics at Jordanian public schools. To achieve the purpose of the study, a pre/post-test was constructed to measure students' achievement in mathematics. The test consisted of twenty items on mathematics. The sample of the study comprised (117) sixth grade students in Ruqaya bent Al Rasoul School for girls and Fatima bent el Yaman school for girls in Irbid the first directorate of Education and was distributed into four sections, which were selected purposefully. The sample of the study was divided into four groups (two experimental and two control groups). The experimental group was taught using multi-sensory approach while the control group was taught using the current approach. The sample of the study was (62) students in the experimental group and (55) students in the control group. Those groups were distributed into four purposefully selected sections in Ruqaya bent Al Rasoul School for girls and Fatima bent el Yaman school for girls in Irbid the first directorate of Education. Descriptive statistical analyses were used (Means and Standard Deviation) for the pre and post- tests of students' mathematics test to experimental and control groups. The findings of the study indicated that there were statistically significant differences in the post- test between the control and the experimental groups in favor of the experimental group. The researcher proposed some recommendations to enhance the importance of parental involvement on students' achievement in English language such as conducting further studies on other populations and for a longer time.
\end{abstract}

Keywords: Multi-Sensory Approach; Students with Learning Disabilities

\section{INTRODUCTION: MULTI-SENSORY LEARNING STRATEGY}

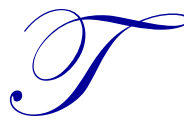

he idea that learning experienced through all the senses is helpful in reinforcing memory has a long history in pedagogy. From the earliest teaching guides, educators have embraced a range of multisensory techniques in order to make learning richer and more motivating for learners. The term is used to refer to any learning activity that combines two or more sensory strategies to take in or express information. Multi-sensory approaches have been particularly valuable in literacy and language learning, for example, in relationships between sound and symbol, word recognition, and the use of tactile methods such as tracing on rough or soft surfaces. The Department for Education and Skills (DfES) (2004) defines multi-sensory as: 'using visual, auditory and kinesthetic modalities, sometimes at the same time'. Kinesthetic refers to perceiving through touch and an awareness of body movements. Teachers working with dyslexic learners have found multi-sensory approaches particularly valuable, as they help learners to make sense of information in a range of ways. Activities that harness all the senses are also an excellent way to include learners with disabilities.

But we stray into a minefield if we try to classify learners into fixed visual, auditory or kinaesthetic stereotypes and teach them accordingly. As Coffield et al (2004) point out in a critical review of learning styles, there is insufficient evidence that such an approach is effective. Indeed, work with learners with learning disabilities focuses on developing all the senses as fully as possible, using techniques such as multi-sensory environments. Case 
studies in this area can be found on the website of the British Educational Communications and Technology Agency (BECTA). Effective teachers select and use the most appropriate approach for the learning task and the learners' situation. In particular, multimedia resources can promote inclusive learning if accessibility features are built in. This can enable learners with hearing or visual impairments to use the same resources as others.

The works of Sweller (1999) and Mayer (2001) are of particular interest to those who develop multimedia resources. Sweller's findings are relevant to those designing learning resources about technically challenging material. He advocates using worked examples, avoiding redundant information (to reduce cognitive load) and using auditory as well as visual information. Mayer concludes that there is growing evidence that well designed multimedia resources lead to deeper learning than traditional verbal-only messages. He offers the following guidance on what constitutes good design. We use 'teaching and learning' and 'teacher' as generic terms to include: teaching, training and learning teachers, tutors, trainers, lecturers and instructors in the further education (FE) system.

\section{Significance of the Study}

Teachers know that students learn in different ways. In order for instruction to reach all students, teaching methods must relate to each child's own learning preference style. Willis and Johnson (2001) stated that students may have more than one inelegancy and this result in a deeper and richer understanding of mathematical concepts through multiple representations; enables all students to learn mathematics successfully and enjoyably; allows for a variety of entry points into mathematical content; and focuses on students' unique strengths. Knowing that no one method of learning is appropriate for all children, teachers should have a variety of mathematics strategies from which to choose, therefore appealing to all learning preference styles. Using a variety of materials allows students to gain experience for understanding and using mathematics. For these reasons, school systems encourage their teachers to search for new and better ways to help children learn. Many ways to meet these needs are offered by NCTM (2000). The set of standards for pre-kindergarten through grade two (2) suggests "schools should furnish a variety of materials so children can connect learning to what they already know. Recommended materials are blocks and clay, playing games and doing puzzles, listening to stories, and engaging in dramatic play, music, and art".

\section{Statement of the Problem}

To learn mathematics, students need to internalize ideas using methods that are meaningful to them. They need the abstract brought to the concrete level for understanding. The use of math manipulatives can be one method to help students accomplish this. Students become active participants of their own learning and formation of idea concepts. Manipulatives can be used to teach to different modalities at the same time, thus reaching a larger percentage of students during instruction. The researcher conducted this study to investigate the positive gains in mathematics achievement of sixth grade students who use a multi-sensory approach to addition.

\section{Purpose of the Study}

The purpose of this study is to investigate the effect of using Multi-Sensory Approach in teaching students with learning disabilities on the sixth grade students' achievement in mathematics at Jordanian public schools.

\section{Question of the Study}

Are there any statistically significant differences $(\alpha \leq 0,05)$ in the sixth grade students' performance in mathematics due to the teaching strategy they are exposed to (using multi-sensory approach and traditional way)?

\section{LITERATURE REVIEW}

The belief that teachers need to include in each teaching presentation at least three basic learning modalities (auditory, visual, and tactile), to meet the needs of most students, is a common thread among researchers. (GadtJohnson, 2000). 
Some researchers mentioned that good lessons using manipulative don't just happen. They are the product of much advance thought and preparation. Some of the work happens years or months in advance as teachers receive training on how to incorporate manipulative into their instruction; other advance work happens the day or night before a lesson is taught. (Stein, Bovalino \& Smith, 2001).

The National Council of Teachers of Mathematics in their 2000 Principles and Standards states:

Concrete models can help students represent numbers and develop number sense; they can also help bring meaning to students' use of written symbols and can be useful in building place-value concept. But using materials, especially in a rote manner, does not ensure understanding. (NCTM, 2000).

Computer instantiated manipulative (CIM) may be an alternative to concrete manipulative to solve openended math problems, particularly with computers in most schools and classrooms. Takahashi (2000) examined eighteen (18) fourth grade children as they sought to find all eighteen (18) ways to cover an equilateral triangle using three (3) blue pattern blocks and three (3) green pattern blocks. Nine (9) children worked alone on computers; nine (9) children worked in groups of three (3) with manipulative to solve this problem. The study found that the children working on the computers found more solutions and spent more time on task before wanting to stop. Working on the computer facilitated better learning opportunities because it printed out each solution the students found; the manipulative groups needed to color a sample triangle for each solution they found. The manipulative groups also had to take apart each solution to reuse the pattern blocks. While this study showed that computers might be a promising tool equivalent to concrete manipulative, it did have a limitation. This study applied to small groups only. A future study could involve looking into classroom situations.

Virtual manipulative are visual representations for computer programs. Dynamic visual representation can be manipulated in the same ways as concrete manipulative. This enables the user to make meaning and see relationships as a result of one's own actions. For students in grades four (4) through eight (8), the use of virtual manipulative may remove the connotation of "playing with blocks." Older students may view the use of virtual manipulative as more sophisticated than using manipulative in their concrete form. (Moyer, Bolyard \& Spikell, 2002)

The National Council of Teachers of Mathematics agrees with the use of technology in the classroom, and likens it to the use of concrete materials. Technology can help students develop number sense, and it may be especially helpful for those with special needs. For example, students who may be uncomfortable interacting with groups or who may not be physically able to represent numbers and display corresponding symbols can use computer manipulative. (NCTM, 2000)

In a study comparing traditional instruction to computer-enhanced instruction to sixteen (16) first graders, Shults (2000) found no significant difference upon t-test comparison of the mean percentile scores. The control group's mean score was higher than the treatment group's mean score. This was attributed to student disinterest in the software in the latter part of the experiment. The belief that teachers need to include in each teaching presentation at least three (3) basic learning modalities (auditory, visual, and tactile), to meet the needs of most students, is a common thread among researchers. (Gadt-Johnson, 2000; Willis, 2001).

Baker \& Beisel (2001) investigated the ways children understand the concept of average. Using a traditional approach with problem solving, a concrete approach with manipulative, and a visual approach with computer-spread sheets, lessons on mean were taught to twenty- two (22) children in grades four (4) through six (6). Differences among pre-test and post-tests found some advantage in the use of visual instructional style. In most classroom work, we teach to three (3) modalities: verbal, visual, and physical. These modalities have different capacities for memory storage; while the verbal modality is limited, the visual modality is nothing short of phenomenal.

The visual modality seems capable of producing immediate comprehension almost effortlessly. Hence, the saying, a picture is worth a thousand words. (Jones 2000). 
When students are able to represent a problem or mathematical situation in a way that is meaningful to them, it becomes more accessible. Using representation - whether drawings, mental images, concrete materials, or equations-helps students organize their thinking and try various approaches that may lead to a clearer understanding and a solution. (Fennell \& Rowan, 2001)

The use of manipulative in teaching mathematics has become very prominent in the past decade. Through many studies, manipulatives have shown to be beneficial in mathematics. Students who use manipulatives in their mathematics classes usually outperform those who do not. The increase in performance is evident in all grade levels, ability levels, and topics. The use of manipulative also increases scores on retention and problem solving tests. Finally, attitudes toward mathematics are improved when students are instructed with concrete materials by teachers knowledgeable about their use.

Constructivist teachers believe there are practical alternatives to drill and practice that combine the teaching of math facts with meaningful mental engagement. (Wakefield, 2001). Mather \& Goldstein (2001) recommended using the Touch Math approach with children who have weakness in the processing block. They benefit from a multi-sensory approach to learning math facts. The visual, auditory, and motor skills of the symbolic blocks are used to aid memorization. Hanrahan (2000) discussed research that had success teaching addition and subtraction to a small group of mildly to moderately intellectually disabled children using an adaptation of the Touch Math approach. The children liked this dot-notation approach because it allowed them to appear as if they were mentally computing as their non-disabled peers were doing. This approach offered these subjects a positive attitude toward computation when it allowed them to be like their peers.

Research has shown that there are three distinctive learning styles: auditory, visual, and tactile. Each student has his or her own unique learning preference style or way of processing and retaining information. When teachers use strategies for all learning styles, individual students are able to learn through their strongest modality. Research has also shown that elementary school children learn best in a tactile/kinesthetic style. When students can manipulate and experience conceptual information through activities, only then, will they learn and retain information more readily. Although this type of learning style is used throughout life, it becomes less dominant as the visual and auditory modalities develop.

This study supports recent research that proves a multi-sensory approach during instruction increases mathematics achievement. An example of examining the impact of a multi-sensory approach to teaching reading is exemplified in a study by Dev, Doyle, and Valente (2002). They used the Orton-Gillingham technique (Institute for Multi-sensory education, 2000), which involves visual, auditory, and kinesthetic modalities, with first grade children at the special education level. These children improved enough in their reading abilities to advance them out of the special education level. The maintenance of the gains that they achieved with the use of the multi-sensory approach was evaluated after a two year period. None of the children had returned to special education classes (Dev et al., 2002).

Joshi, Dahlgren, and Boulware- gooden(2002) examined the effects of using a multi-sensory approach to teaching reading with first graders. Language Basics: Elementary, based on Orton- Gillingham and Alphabetic phonics, is the multi-sensory method used for this study as the treatment. A based reader was used for the control group. When given tests of phonological awareness, decoding, and reading comprehension, the treatment group performed better than the control group. The authors noted and concluded that using the multi-sensory approach was effective with the first group.

\section{DESIGN AND METHODOLOGY}

Here the researcher discussed the procedures that she used to conduct the study. She described the study population, sample, variables, instrument, procedures and the statistical analyses that were used in the study. 


\section{Population of the Study}

The population of the study consisted of all sixth grade students in Irbid the first Directorate of Education enrolling in the second semester 2011/2012 totaling (3700) students.

\section{Sample of the Study}

The sample of the study consisted of (117) sixth grade students in Ruqaya bent Al Rasoul School for girls and Fatima bent el Yaman school for girls in Irbid the first directorate of Education and was distributed into four sections, which were selected purposefully. Table (1) shows the students' sample distribution.

Table 1: The sample distribution

\begin{tabular}{|l|c|c|c|}
\hline \multicolumn{1}{|c|}{ School } & Control group & Experimental group & total \\
\hline Ruqaya bent Al Rasoul School for girls & 30 & 32 & 62 \\
Fatima bent el Yaman school for girls & 26 & 29 & 55 \\
\hline Total & & & 117 \\
\hline
\end{tabular}

\section{Design of the Study}

The participants of the study were divided into two groups, experimental and control. The participants of the experimental group were taught mathematics using Multi-Sensory Approach for (8) weeks, While the participants of the control group were taught by the traditional way for the same period. A pre-test was given before the application of the treatment to both groups to make sure they are equivalent and the same test was administered as a post-test after applying the treatment to see whether the using of Multi-Sensory Approach for teaching mathematics had any influence on the experimental groups.

\section{Instrument of the Study}

The researcher used two strategies for teaching mathematics: Using Multi-Sensory Approach and the traditional strategy. Then the researcher designed a test based on the instructional material of the sixth grade mathematic book and collected the data. Validity and reliability were ensured. Both groups; the experimental group as well the control group, were taught by their teachers. The subjects in both groups took a pre-test to determine their actual level before starting the experiment, and the same test was administered as a post-test at the end of the experiment to assess subjects' achievement. The time interval between the pre-test and the post-test was (8) weeks; a period long enough to minimize the effect of the pre-test on the results and conclusions of the experiment.

\section{Reliability of the Instrument}

To ensure the test reliability, the researcher followed test/retest technique. The researcher applied it to a pilot sample of (15) student who were excluded from the study with a two-week period between the test and the retest. The reliability of the test was calculated using correlation coefficient and found to be 0.87 . This is appropriate for conducting such a study.

\section{Validity of the Instrument}

The researcher validated the instrument by submitting it to a jury of two supervisors of mathematics and two teachers of mathematics at Irbid the first Directorate of Education. The researcher asked the referees to write their comments if there are any.

\section{Instructional Material}

The instructional material was the sixth grade mathematic book which includes six chapters, but the researcher will cover at least 2 chapters during the application period. 


\section{Procedures of the Study}

There are two groups of students: one experimental group and one control group. Both groups received 8 weeks of instruction of mathematics. Students in the experimental group were taught mathematics using multisensory approach. While Students in the control group were instructed using the traditional way. After the treatment the two groups were exposed to a post test to see the effect of using multi-sensory approach on students' achievement.

\section{Statistical Analyses}

To answer the study question, descriptive methods (means and standard deviation) were used for pre and post tests for English language vocabulary test for both the experimental and control groups. In addition to a TwoWay ANOVAs the statistics used T- test to show equivalence, Two- Way ANOVAs to answer the research question.

\section{Findings of the Study}

The purpose of this study is to investigate the effect of using Multi-Sensory Approach in teaching students with learning disabilities on the sixth grade students' achievement in mathematics at Jordanian public schools. The researcher followed the equivalent pre /post test two group designs. Therefore, the means, standard deviations and Two-Way ANOVA analysis of variance were used to analyze data. The results were displayed based on the questions of the research. To determine if there is a statistically significant difference between the experimental and control groups, a t-test for independent samples was conducted. Table 2 shows the results.

Table 2: Means and Standard Deviations of the Achievement of two Groups on the Pre-test

\begin{tabular}{|l|l|c|c|c|c|c|c|}
\hline & GROUP & $\mathbf{N}$ & Mean & $\begin{array}{c}\text { Std. } \\
\text { Deviation }\end{array}$ & $\mathbf{t}$ & df & $\begin{array}{c}\text { Sig. } \\
\text { (2-tailed) }\end{array}$ \\
\hline Pre & Experimental & 62 & 55.35 & 7.05 & .461 & 111 & .646 \\
\hline & Control & 55 & 54.74 & 7.09 & .461 & 109.165 & .646 \\
\hline
\end{tabular}

Table 2 indicated that the difference between experimental and control groups is not statistically significant at $(\alpha=0.05)$. Thus, since the difference was not significant, the two groups were assumed equivalent and the sample was divided into two groups, an experimental and a control group. The means for the experimental group was 55.35 while it was for the control group 54.74, which means that there were nearly the same. The experimental group which were taught using Multi-Sensory Approach consisted of (62) students while the control group consisted of (55) students. So Table (2) above showed that there are no statistically significant differences in pre test due to group variable. Table 2 also showed that the difference between the achievement of the two groups on the pre-test was not statistically significant at $(\alpha=0.05)$. Since there was no statistically significant difference between the control and experimental groups on the pre-test, it was for the experimental (.646) which was more than (.05) and it was for the experimental (.646) too which is also above (.05) so, the groups were assumed equivalent.

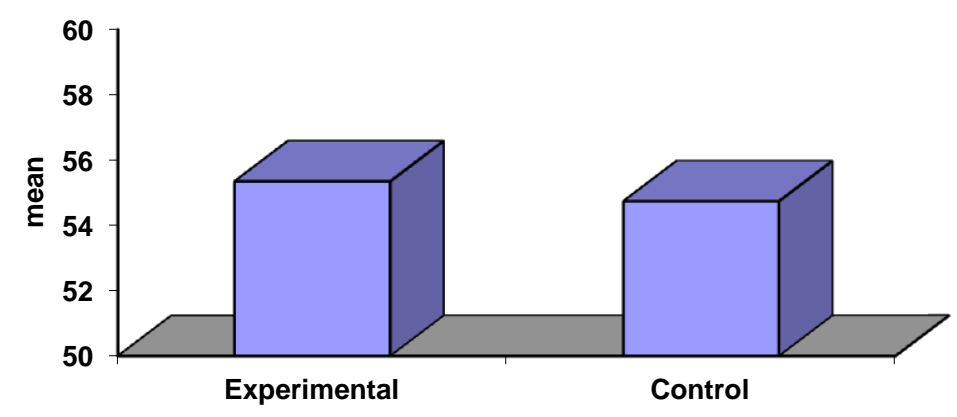

Diagram 1: Experimental and control groups mean on pre-test 
Diagram 1 showed that there were no statistically significant differences in students' achievement between experimental and control groups in the pre test which means that they were nearly equivalent. To determine if the two groups are equivalent in their achievement in mathematics due to the using of Multi-Sensory Approach, a posttest was conducted and Table 3 presents the results.

Table 3: t-test Results of the Experimental and the Control Groups on the Post-test.

\begin{tabular}{|l|l|c|c|c|c|c|c|}
\hline & GROUP & N & Mean & $\begin{array}{c}\text { Std. } \\
\text { Deviation }\end{array}$ & t & df & $\begin{array}{c}\text { Sig. } \\
(\text { 2-tailed })\end{array}$ \\
\hline Post & Experimental & 62 & 85.58 & 7.90 & 5.318 & 111 & .000 \\
\hline & Control & 55 & 76.15 & 10.87 & & & \\
\hline
\end{tabular}

Table 3 showed that there was a statistically significant difference at $\alpha=0.05$ between the achievement of the experimental group and that of the control group on the post-test in favor of the experimental group. This difference indicated that using Multi-Sensory Approach may have had a positive effect on students' achievement. The mean score for the experimental group on the post-test was 85.58 while that of the control group was 76.15. Table 3 also showed that there was a statistically significant difference between the experimental group and the control group on the post-test, was significantly better than that of the control group. The researcher also conducted a two-way analysis of variance to analyze the post-test achievement scores of the two groups. Table 3 showed the results. So table above shows there are statistically significant differences in post test due to group variable in favor of the experimental group.

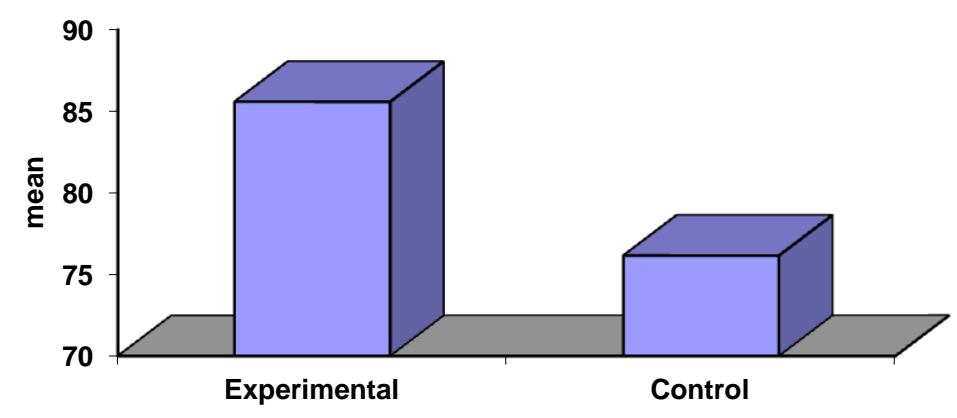

Diagram 2: Experimental and control groups mean on post-test

Diagram 2 shows that the experimental group got a higher mean in the post test which proves that using Multi-Sensory Approach is effective in teaching mathematics.

\section{CONCLUSION}

This study sought to discover if sixth grade students taught mathematical concepts such as addition through a multi-sensory approach would show higher mathematical achievement than those who were not. After analyzing the data, it was discovered that there was a significant difference between the pre-test and post-test scores of subjects who had participated in the multi-sensory approach to learn addition and other mathematical concepts than those who had not participated. The Multi-Sensory approach to teaching mathematics to sixth graders showed a significant level of mathematical achievement gained.

Teachers of mathematics have the important job of presenting curriculum material in many different modalities so all students are capable of learning. The Multi-Sensory approach appeals to children through auditory, visual, and tactile senses. The importance of this research study will give classroom teachers one more instructional strategy to use. It will assist them to be prepared to meet the diverse needs of all students learning the concept of mathematics such as addition. 


\section{AUTHORS INFORMATION}

Dr. Majeda Al Sayyed Obaid, Ph.D., Assistant Professor, Faculty of Educational Sciences, Irbid National Universitiy, Jordan.

\section{REFERENCES}

1. Baker, J. \& Beisel, R. (2001, January). An experiment in three approaches to teaching average to elementary school children. School Science and Mathematics, 101(1), 23-31.

2. Coffield, F., Moseley, D., Hall, E. and Ecclestone K. (2004) Learning styles and pedagogy in post-16 learning. A systematic and critical review, London: Learning and Skills Research Centre.

3. Dev, P.C., Doyle, B.A., \& Valente, B. (2002). Labels needn’t stick: "At-risk" first graders rescued with appropriate intervention. Journal of Education for Students Placed at Risk, 7(3), 327-332.

4. Fennell, F. \& Rowan, T. (2001, January). Representation: An important process for teaching and learning mathematics. Teaching Children Mathematics, 7(5), 288-292.

5. Gadt-Johnson, C. \& Price, G. (2000). Comparing students with high and low preferences for tactile learning. Education, 120(3), 581-585. Retrieved Jan 20, 2012, from Academic Search Elite database.

6. Hanrahan, J. (2000). An analysis of an imprinted-dot approach to teaching arithmetic to intellectually disabled children and its potential for facilitating inclusion. Retrieved Jan 20, 2012, from http://www.isec2000.org.uk/abstracts/papers_h/hanrahan 1.htm

7. Jones, F., Jones, J. \& Jones, J. (2000). Tools for teaching. Hong Kong: Fredric H. Jones \& Associates, Inc.

8. Joshi, R. M., Dahlgren, M., \& Boulware- Gooden, R. (2002). Teaching reading in an inner city school through a multi-sensory teaching approach [Electronic Version]. Annals of Dyslexia, 52,229-42.

9. Mather, N. \& Goldstein, S. (2001). Learning disabilities and challenging behaviors: A guide to intervention and classroom management. Baltimore: Paul H. Brookes Publishing.

10. Moyer, P., Bolyard, J. \& Spikell, M. (2002, February). What are virtual manipulatives? Teaching Children Mathematics, 8,372-377.

11. National Council of Teachers of Mathematics. (2000). Principles and standards for school mathematics. Reston, VA: Author.

12. Shults, P. (2000). Teaching first grade computation: A comparison of traditional instruction and computer enhanced instruction (Report No. SE 063887). (ERIC Document Reproduction Service No. ED 443705

13. Sweller, J. (1999) Instructional Design in Technical Areas, Australian Council for Educational Research, Victoria.

14. Takahashi, A. (2000). Open-ended problem solving and computer instantiated manipulatives (CIM) Research thesis. University of Illinois at Urbana-Champaign. Retrieved Jan 20, 2012, from http://www.students.edu.uiuc.edu/takahash/mcme9-cim.pdf

15. Wakefield, A. (2001, May). Teaching young children to think about math. Principal, 80, 26-29.

16. Willis, J. \& Johnson, A. (2001, January). Multiply with MI: Using multiples intelligences to master multiplication. Teaching Children Mathematics, 7, 260-270.

17. Stein, M., Bovalino, J. \& Smith, M. (2001, February). One piece of the puzzle. Mathematics Teaching in the Middle School, 6, 356-361. 